\title{
Doege-Potter syndrome: a rare presentation of a solitary fibrous tumor of the pleura
}

\author{
Síndrome de Doege-Potter: uma apresentação rara de tumor fibroso solitário da \\ pleura
}

Liu Estradioto ${ }^{1}$, Rodrigo Bettega de Araujo ${ }^{1 *}{ }^{\circ}$, Nelson Bergonse Neto ${ }^{1}$, Vanessa Bettega de Araújo ${ }^{1}$, Marlos de Souza Coelho', Larissa Luvison Gomes da Silva' ${ }^{1}$

\begin{abstract}
Solitary fibrous tumors of the pleura usually have a benign behavior, although some may present malignant characteristics - recurrences, metastases, and paraneoplastic syndromes. When a solitary fibrous tumor is responsible for the development of hypoglycemia, we have a case of Doege-Potter syndrome. We describe a case of a male patient that presented recurring and severe hypoglycemia, being also diagnosed with an extensive intrathoracic mass, which was proven to be a solitary fibrous tumor of the pleura. The treatment, through the maintenance of proper serum levels of glucose (administration of solutions with glucose and steroids), followed by the surgical resection of the tumor, promoted the complete resolution of the hypoglycemia episodes. The early recognition of this condition and the proper treatment is essential for a good clinical outcome. It is important to underscore that the multidisciplinary evaluation (oncologists, radiologists, surgeons, and pathologists) of rare tumors is recommended to achieve better therapeutic results.
\end{abstract}

Keywords: Solitary fibrous tumor; Pleural; Paraneoplastic endocrine syndromes; Thoracic neoplasms.

\begin{abstract}
RESUMO
Os tumores fibrosos solitários da pleura costumam ter um comportamento benigno, embora alguns possam apresentar características malignas - recidivas, metástases e síndromes paraneoplásicas. Quando um tumor fibroso solitário é responsável pelo desenvolvimento de hipoglicemia, temos um caso de síndrome de Doege-Potters. Descrevemos o caso de um paciente do sexo masculino que apresentou hipoglicemia recorrente e grave, sendo diagnosticado também uma extensa massa intratorácica, que se comprovou ser um tumor fibroso solitário da pleura. O tratamento, por meio da manutenção de níveis séricos adequados de glicose (administração de soluções com glicose e esteroides), seguido da ressecção cirúrgica do tumor, promoveu a resolução completa dos episódios de hipoglicemia. O reconhecimento precoce dessa condição e o tratamento adequado são essenciais para uma boa evolução clínica. É importante ressaltar que a avaliação multidisciplinar (oncologistas, radiologistas, cirurgiões e patologistas) de tumores raros é recomendada para obter melhores resultados terapêuticos.
\end{abstract}

Descritores: : Tumor fibroso solitário da pleura; Síndromes endócrinas paraneoplásicas; Neoplasias torácicas.

\footnotetext{
1. Hospital Santa Casa de Misericórdia de Curitiba, Thoracic Surgery - Curitiba - Paraná - Brazil.

Financial support: none to declare.

Conflicts of interest: The authors declare no conflict of interest relevant to this manuscript.

Correspondence author: Rodrigo Bettega de Araujo, Hospital Santa Casa de Misericórdia de Curitiba, Thoracic Surgery - Curitiba - Paraná - Brazil.

E-mail: rodrigobettega@hotmail.com
} 


\section{INTRODUCTION}

Solitary fibrous tumors are cancers that originate from submesothelial mesenchymal cells with fibroblast differentiation and appear in several places in the organism (abdominal cavity, pelvic cavity, etc.); although, most are intrathoracic. Regarding their biological behavior, they are usually benign. However, about $15 \%$ to $20 \%$ of them present a malignant behavior with recurrence and distant metastasis. ${ }^{1}$

Solitary fibrous tumors of the pleura (SFTP) are unusual cancers, and even more unusual are the ones associated with hypoglycemia. DoegePotter syndrome is characterized by hypoglycemia (usually severe and recurring) and is caused by the inappropriate secretion of insulin-like growth factor type 2 (IGF-II) by a solitary fibrous tumor. ${ }^{2}$ This syndrome occurs in less than $5 \%$ of the solitary fibrous tumors of the pleura and the literature includes around 100 reported cases. ${ }^{2,3}$

We describe the case of a patient presenting recurring and severe hypoglycemia episodes that discovered an enormous chest tumor. Although lung cancer has been considered one of the possible diagnosis, the hypoglycemia and the good clinical status of the patient have made us consider the diagnosis of Doege-Potter syndrome. After tumor board discussion, we performed resection of the mass and the patient had an excellent outcome no longer having hypoglycemia episodes. This is the second case reported in the Brazilian literature of Doege-Potter syndrome but the first related to a benign pleural solitary fibrous tumor.

\section{CASE REPORT}

Male patient, 52-years-old, sent to our thoracicsurgery clinic for evaluation of the voluminous thoracic opacity located at the left hemithorax detected in a chest X-ray. He also presented symptoms that were compatible with the hypoglycemia condition (collapse, sweating, and visual blurring) for 1 year, associated to an 8-kilo weight loss in 4 months. Former smoker, with a smoking history of 30 yearspack. History of caustic soda intake 30 years ago and esophageal stricture with the necessity of periodic dilatations. He denied allergies or the regular use of medicines.

His chest X-ray (Figure 1) presented hypotransparency at his left lung base up to the middle third of the respective hemithorax. The chest tomography (Figure 1) presented a low-density expansive lesion, of $16 \times 12 \times 11 \mathrm{~cm}$, reaching the lower lung lobe and the lingula with calcification inside it.

He presented normal laboratory exams, except for a serum glucose dosage of $34 \mathrm{mg} / \mathrm{dl}$. The investigation for hypoglycemia presented normal levels of C-peptide and serum insulin. During his last hospitalization, he presented severe symptomatic hypoglycemia episodes (glucose levels under 40mg/ dl), which was compensated with an intravenous solution administration of glucose $10 \%$ and corticosteroid therapy (prednisone 10mg/day) until the surgical resection day.

We also performed a flexible video-bronchoscopy, which presented a caliber reduction of the segmental bronchi of the left lower lobe, bronchoalveolar lavage with negative cytology for malignancy, and inconclusive transbronchial biopsy. Then the patient was submitted to thoracotomy with the resection of the tumorous mass and of the adjoining lung tissue (peripheral portions of the left lower lobe). The lesion was attached to the mediastinal fat, but most of its surface was free. The resection's product weighted 1.66 kilos (Figure 1). The histopathological evaluation revealed fusocellular nodular mesenchymal cancer with a focal presence of ischemic necrosis and fibrosis/ sclerosis with dystrophic calcification; absence of atypical mitosis; absence of angiolymphatic compromise/embolization; free surgical capsule and margins. The immunohistochemical evaluation revealed histological features of solitary fibrous tumor, with diffuse immunoexpression of CD34 and STA6 (Figure 2), without malignancy criteria in the sample.

After 10 months of postoperative monitoring, the patient was clinically well and did not present any other hypoglycemia episode. Imaging follow-up did not present signs of recurrence or metastases until now.

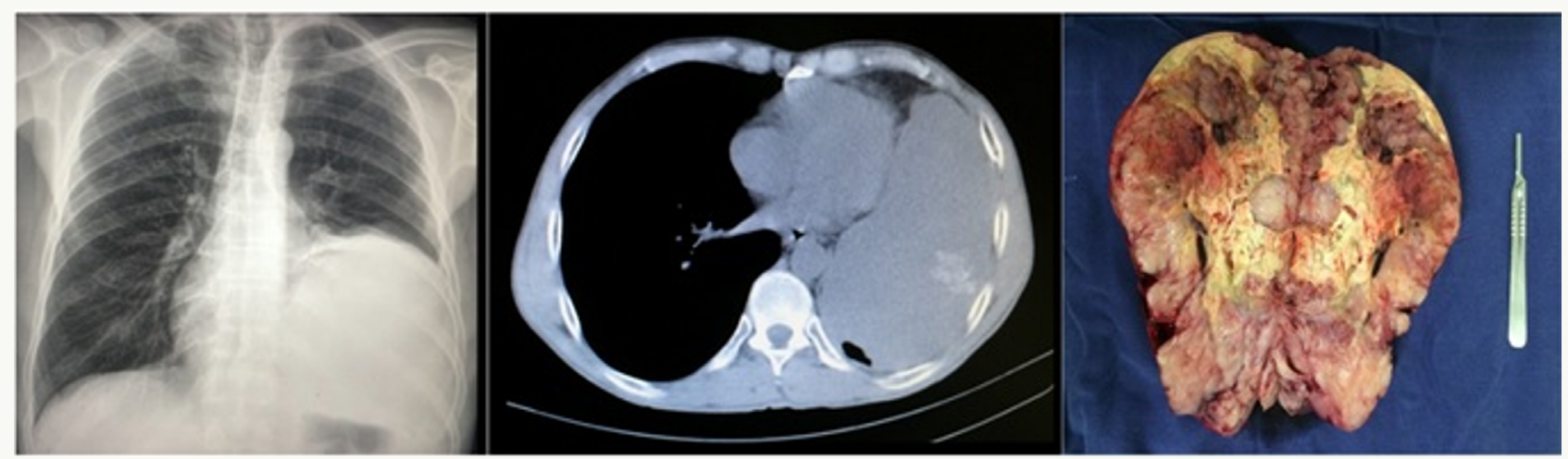

Figure 1. Left: chest X-ray presenting a bulky opacity at the left hemithorax base. Center: chest tomography presenting a bulky mass in the left hemithorax, of regular shape, with low density, and some calcifications inside it. Right: surgical specimen. 

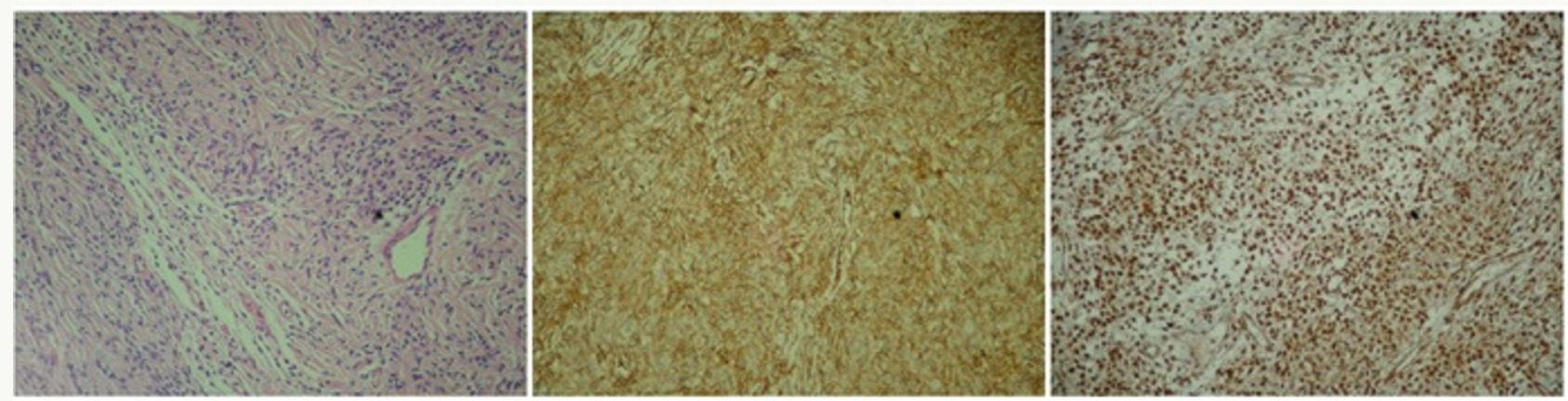

Figure 2. Slide stained in hematoxylin-eosin (left): the fusocellular cells' aspect is highlighted. Slides of the immunohistochemical panel: CD34 (center) and STAT6 (right).

\section{DISCUSSION}

The association of a clinical condition of hypoglycemia with solitary fibrous tumors, usually of the pleura, resulting from the inappropriate secretion of IGF-II is known as Doege- Potter syndrome. ${ }^{2}$

Doege and Potter firstly described it in 1930. We believe that this syndrome occurs in less than $5 \%$ of the solitary fibrous tumors of the pleura. The literature includes around 100 reported cases thereof. 2,3

The clinical course of patients with solitary fibrous tumor of the pleura is mostly benign with an excellent prognosis. ${ }^{1}$ However, the presence of associated hypoglycemia, like in the syndrome described herein, may result in serious complications caused by severe hypoglycemia, usually recurring, due to the delay and difficulty in establishing the diagnosis of its etiology, considering the rarity of the condition described herein.

Regarding clinical aspects, the SFTP appears as a slow-growing mass, usually asymptomatic, but usually in adults in their $6^{\text {th }}$ or $7^{\text {th }}$ life decades. These tumors may cause pain and symptoms caused by the adjacent structures compression. ${ }^{1,4}$ Two thirds of them develop from the visceral pleura and one third from the parietal pleura. ${ }^{5}$

The diagnosis suspicion results from the findings of the image tests, initially the chest X-ray, which detects a mass or opacity, and then the chest tomography, which accurately defines the mass' characteristics, location, and relation with the adjoining structures. The definitive diagnosis is only possible with the histopathology associated to the immunohistochemistry. These tumors have a strongly positive reaction to CD-34, CD-99, and vimentin, but a negative one to the cytokeratins AE1 and AE2, synaptophysin, and calretinin. This negativity excludes the epithelial and mesothelial origins. ${ }^{5}$ Our case presented a diffuse immunoexpression to CD34 and STAT6, and a negative one to AE1, AE3, AML, 1A4, Desmin, E29, and protein S100.

The treatment has two fronts: the compensation of the hypoglycemic conditions and resection of the tumor. The hypoglycemia must be compensated through the administration of solutions with glucose, glucagon injections, and therapy with glucocorticoids, which are options to keep a proper glycemic control. ${ }^{6}$
The treatment of choice was the complete surgical resection of the SFTP with free margins of 1 to $2 \mathrm{~cm}$, which usually results in the complete resolution of the hypoglycemia conditions, which is the most important prognostic factor. Annual chest X-rays are recommended for postoperative monitoring., ${ }^{5,6}$

In cases where complete surgical resections are not possible due to tumorous infiltration of noble structures and/or the presence of metastases, incomplete resections followed by chemo and/ or radiotherapy may be an option to treat hypoglycemia. In case of recurrence or metastases, or with patients that is not fit for surgery, the treatment is glucocorticoids and/or glucagon for hypoglycemia associated to chemo and/or radiotherapy for the lesion. Tumorous recurrence and/or the presence of metastases are associated to a worse prognosis. ${ }^{7}$

It is important to note that the multidisciplinary evaluation (oncologists, radiologists, surgeons, and pathologists) of unusual tumors is strongly recommended to achieve better therapeutic results. ${ }^{1}$

\section{REFERENCES}

1. Schmid S, Csanadi A, Kaifi JT, Kübler M, Haager B, Kayser G, et al. Prognostic factors in solitary fibrous tumors of the pleura. J Surg Res. 2015 May;195(2):580-7.

2. Schutt RC, Gordon TA, Bhabhra R, Cathro HP, Cook SL, McCartney CR, et al. Doege-Potter syndrome presenting with hypoinsulinemic hypoglycemia in a patient with a malignant extrapleural solitary fibrous tumor: a case report. J Med Case Rep. 2013 Jan;7:11.

3. Scrimgeour LA, Grada Z, Aswad BI, Ng T. Lessons learned from an untreated "benign" thoracic tumor. Ann Thorac Surg. 2017 Feb;103(2):e135-e7.

4. Moreira BL, Monarim MAS, Romano RFT, Mattos LA, D'Ippolito G. Doege-Potter syndrome. Radiol Bras. 2015 Jun;48(3):195-6.

5. Zafar $\mathrm{H}$, Takimoto $\mathrm{CH}$, Weiss $\mathrm{G}$. Doege-Potter syndrome: hypoglycemia associated with malignant solitary fibrous tumor. Med Oncol. 2003;20(4):403-8. 
6. Mohammedi K, Abi Khalil C, Olivier S, Benabad I, Roussel R, Marre M. Paraneoplastic hypoglycemia in a patient with a malignant solitary fibrous tumor. Endocrinol Diabetes Metab Case Rep. 2014;2014:140026.
7. Khowaja A, Johnson-Rabbett B, Bantle J, Moheet A. Hypoglycemia mediated by paraneoplastic production of Insulin like growth factor-2 from a malignant renal solitary fibrous tumor - clinical case and literature review. BMC Endocr Disord. 2014Jun;14:49. 